\title{
Efeitos da aplicação periódica da simulação in situ para educação permanente em ressuscitação cardiopulmonar no contexto da hemodiálise
}

\author{
Fabiana Pisciottani' ${ }^{1}$, Cleidilene Ramos-Magalhães ${ }^{1}$, Ana Elizabeth Figueiredo ${ }^{2}$ \\ ${ }^{1}$ Universidade Federal de Ciências da Saúde de Porto Alegre. Porto Alegre. Brasil \\ ${ }^{2}$ Pontifícia Universidade Católica do Rio Grande do Sul. Porto Alegre. Brasil
}

Como citar este artículo:

Pisciottani F, Ramos Magalhães C, Figueiredo AE.

Efeitos da aplicação periódica da simulação in situ para educação permanente em ressuscitação cardiopulmonar no contexto da hemodiálise. Enferm Nefrol. 2020 Jul-Sep;23(3):274-284

\section{Resumo}

Introdução: A parada cardiorrespiratória é um evento crítico para o paciente dialítico, que necessita de uma equipe de enfermagem na hemodiálise apta a realizar 0 procedimento de ressuscitação cardiopulmonar. Justifica-se nesse contexto a educação permanente em enfermagem, que por meio da simulação in situ, pode contribuir com a construção das competências em ressuscitação cardiopulmonar.

Objetivo: Verificar se diferentes periodicidades de formação utilizando a simulação in situ, influenciam na construção de competências para a ressuscitação cardiopulmonar no ambiente da hemodiálise.

Material e Método: Trata-se de um estudo experimental não randomizado, realizado com profissionais de enfermagem de uma unidade de diálise situada em um Hospital Universitário de grande porte da região sul do Brasil. Os participantes foram alocados em 3 grupos que receberam periodicidades diferentes de intervenção ( 2 , 4, e 8 meses).

Resultados: Os resultados apontaram diferenças estatisticamente significativa na análise do conhecimento, no grupo de periodicidade de 4 meses. $\mathrm{Na}$ avaliação das habilidades, observou-se resultado

\section{Correspondencia:}

Fabiana Pisciottani

Email: faenfpisciottani@gmail.com significativo $(p=0,048)$ para o grupo de periodicidade de 4 meses, na técnica da compressão torácica.

Conclusão: Com este estudo demonstramos que a simulação in situ promoveu a construção de competências no intervalo a cada 4 meses, corroborando com o fato de que a aprendizagem por meio da experimentação e a reflexão, e dentro do contexto profissional, podem contribuir com a educação permanente em saúde. Mais estudos no contexto da diálise são necessários para confirmar e generalizar os achados.

Palavras chave: educação continuada; simulação, ressuscitação cardiopulmonar; hemodiálise.

Effects of the periodic application of in situ simulation for permanent education in cardiopulmonary resuscitation in the context of haemodialysis

\section{Abstract}

Introduction: Cardiac arrest is a critical event for the dialysis patient who needs a nursing staff in haemodialysis able to perform cardiopulmonary resuscitation. In this context, permanent nursing education is justified, which, through in situ simulation, can contribute to the construction of skills in cardiopulmonary resuscitation.

Objective: To verify whether different training periods using in situ simulation, influence the construction 
of skills for cardiopulmonary resuscitation in the haemodialysis environment.

Material and Method: A non-randomized experimental study was carried out with nursing professionals from a dialysis unit located in a large University Hospital in the southern region of Brazil. Participants were allocated to 3 groups that received different intervals of intervention $(2,4$, and 8 months).

Results: The results showed statistically significant differences in the analysis of knowledge, in the 4-month group. In assessing skills, a significant result $(p=0.048)$ was observed for the 4-month group, using the chest compression technique.

Conclusion: This study shows that in situ simulation promotes the construction of skills in an interval of 4 months, corroborating that learning through experimentation and reflection, and within the professional context, can contribute to permanent education in health. More studies are needed in the context of dialysis to confirm and generalize the findings.

KEYWORDS: continuing education; simulation, cardiopulmonary resuscitation; haemodialysis.

\section{Introdução}

A doença cardiovascular em geral e a parada cardiorrespiratória (PCR), em particular, são uma das principais causas de mortalidade entre aqueles com doença renal crônica (DRC)1. Entende-se que, os pacientes em diálise são um grupo especial de indivíduos com elevado risco de morte cardíaca súbita².

Karnik et al. demonstraram que de 400 PCRs que aconteceram em unidades de diálise, 386 foram consideradas de etiologia cardíaca ${ }^{3}$. Os mecanismos cardiovasculares envolvidos na DRC ocorrem basicamente devido à uremia crônica, deposição de cálcio e fosfato nas artérias coronárias, anemia e sobrecarga vascular. Estes fatores associados à hipertensão arterial e diabetes mellitus, causam aumento da ocorrência de aterosclerose, cardiomiopatias com hipertrofia ventricular esquerda, e risco de infarto agudo do miocárdio ${ }^{1-6}$. Também foram citados os desequilíbrios eletrolíticos com instabilidade eletrofisiológica, os quais deixam os pacientes propensos à arritmias ${ }^{1,2,6}$, como por exemplo, as baixas concentrações de potássio (em pacientes com concentrações séricas pré diálise baixas ou normais), e cálcio no dialisato, as quais podem causar fibrilação $0^{1,2,3,6}$.

Verificou-se uma frequência de PCR mais alta na primeira sessão de hemodiálise (HD) da semana, esse fato suporta a hipótese de que um intervalo mais longo sem diálise pode aumentar o risco de PCR. A PCR tem incidência maior durante a sessão de HD $\left(81 \%^{3}\right.$ e $\left.70,5 \%{ }^{7}\right)$, do que antes $\left(7 \%^{3}\right.$ e $\left.9,8 \%{ }^{7}\right)$, ou após a sessão $\left(12 \%{ }^{3}\right.$ e $\left.19,6 \%{ }^{7}\right)$, provavelmente por mudanças rápidas nos eletrólitos, alterações de volume, atividade ectópica ventricular e alargamento do intervalo Q-T, os quais precipitam arritmias como a fibrilação, e aumentam o estresse cardíaco $0^{3,7}$.

A PCR é uma preocupação para os pacientes em diálise, porque é um evento clínico com grandes chances de ocorrência, e caracterizado por um alto grau de letalidade ${ }^{8}$. Wong et al. acompanharam o desfecho de pacientes em HD que sofreram $P C R$, e verificaram que $21,9 \%$, destes sobreviveram até a alta hospitalar, e a mediana de tempo de sobrevivência pós alta foi de 5 meses, enquanto $31,3 \%$ dos pacientes sobreviveram 1 ano após a alta?.

A ressuscitação cardiopulmonar (RCP), iniciada pela equipe de diálise, pode aumentar três vezes as chances de sobrevivência e proporcionar um status neurológico favorável no momento da alta hospitalar ${ }^{10}$. Nesse caso, é recomendado que a equipe da unidade de diálise possua formação em RCPli, visto que a sobrevivência dos indivíduos vítimas de PCR pode ser influenciada pelo desempenho dos profissionais que atuam nessas situações ${ }^{12}$.

A frequência insuficiente de formações em RCP e a limitada experiência com PCR dos profissionais que atuam em clínicas de diálise, podem levar à diminuição da confiança na realização da RCP. Outros fatores podem estar relacionados com a incerteza sobre como adaptar procedimentos e técnicas tradicionais de RCP ao ambiente específico da clínica de diálise. São exemplos: a realização de compressões torácicas para pacientes numa cadeira de HD e o gerenciamento do volume sanguíneo no circuito extracorpóreo durante a PCR e a aplicação em segurança do desfibrilador aos pacientes que ainda estão conectados ao monitor de $H D^{10}$. Essas preocupações são endossadas pelo estudo de Pun et al. ${ }^{10}$ que constatou que $81 \%$ dos pacientes receberam RCP pela equipe de diálise, e em 52,3\% 
das vezes o desfibrilador externo automático (DEA) foi aplicado, achado similar também foi encontrado no estudo de Davis et al. ${ }^{7}$, onde o DEA foi aplicado em $53 \%$ dos pacientes.

É evidente que o ambiente da diálise necessita de uma atenção diferenciada no que se refere à metodologia de formação que será aplicada no contexto da educação permanente em RCP. Borges \& Machado observaram que a incorporação de materiais de uso diário relacionados com 0 ambiente de trabalho à formação em RCP foi de grande importância para a aprendizagem, pois permitiu a pratica de habilidades, a identificação de falta de material e falhas na manutenção preventiva de equipamentos ${ }^{13}$.

A simulação é uma metodologia ativa que permite construir o conhecimento baseado na reflexão sobre a prática, a qual é vivenciada dentro de sua abordagem técnica e comportamental ${ }^{14}$. A simulação in situ é um novo escopo da simulação que permite a prática dentro de ambientes clínicos reais, contribuindo assim com a aprendizagem individual e em equipe, reforçando as habilidades necessárias ao próprio contexto de trabalho ${ }^{15,16}$.

Os benefícios da simulação in situ para a formação em RCP estão relacionados com a possibilidade de prática repetitiva e da observação de aspectos consideráveis sobre o desempenho dos profissionais durante a RCP, identificando problemas logísticos e operacionais que envolvem o procedimento ${ }^{17,18}$.

As diretrizes da American Hearth Association (AHA) e European Ressuscitation Council (ERC) recomendam que se realizem formações em RCP a cada dois $a_{0}{ }^{12}$. Contudo, Yang et al. conduziram uma revisão sistemática em profissionais de saúde após a conclusão de um curso de manobras de reanimação, onde avaliou a retenção de conhecimentos e habilidades de RCP no adulto. Nos resultados, verificou que quase todos os estudos relataram taxas variáveis de deterioração das habilidades e conhecimento de 6 meses a 1 ano após a formação ${ }^{19}$. Assim, as competências declinam quando não são aplicadas na prática por um período de tempo. Observou-se após 1 ano de não prática de uma habilidade uma diminuição de $92 \%$ do nível de desempenho, demonstrando que esse efeito aumenta de acordo com o passar do tempo ${ }^{20}$.

Tendo em vista a necessidade de determinar a periodicidade ideal de formações em RCP, o presente estudo abordou o uso de uma intervenção educativa, por meio da simulação na modalidade in situ, para verificar a influência do intervalo entre as formações na construção do conhecimento e habilidades em RCP para os profissionais de enfermagem que atuam no serviço de diálise.

\section{Material e método}

Estudo de abordagem quantitativa, com desenho experimental, não randomizado, longitudinal e prospectivo, que comparou o uso de uma intervenção educativa (simulação in situ), com periodicidades diferentes (2, 4 e 8 meses).

\section{Participantes/população e amostra}

A população do estudo foi composta por 29 profissionais de enfermagem. Destes, 8 (27,5\%) eram enfermeiros, e $21(72,5 \%)$ eram técnicos de enfermagem. A técnica de amostragem foi não probabilística e por conveniência. Excluímos os profissionais que atuavam exclusivamente na gestão da unidade, os que estavam em férias e/ou licenças prolongadas no momento do convite, e os que se ausentaram na formação inicial. Depois de aplicados os critérios, participaram 6 enfermeiros ( $75 \%$ do total de enfermeiros), e 18 técnicos de enfermagem ( $86 \%$ do total de técnicos). Dos 24 participantes incluídos na pesquisa, 20 completaram o plano de intervenções proposto conforme os grupos em que foram alocados. Consideramos como perda do contingente total da amostra, quatro participantes do grupo $A$ por não terem participado na simulação inicial no prazo limite para a análise da periodicidade, restando 4 participantes desse grupo para a coleta da intervenção de $8 / 8$ meses.

Conduzimos o estudo entre agosto de 2016 à julho de 2017. Foi realizado dentro de uma unidade de diálise no Hospital São Lucas da Pontifícia Universidade Católica do Rio Grande do Sul. Segundo dados de 2019, a região sul do país apresentou uma taxa de prevalência estimada crescente de pacientes em diálise (525 pacientes por milhão de população ( $\mathrm{pmp}$ ) em 2014, e 624 pmp em 2017) ${ }^{21}$.

A referida unidade de diálise realiza em média 1.223 sessões de HD por mês, e atende $56,8 \%$ de pacientes do Sistema Único de Saúde. Em torno de $48,5 \%$ das sessões houve algum tipo de complicação intradiálise sendo a mais frequente a hipotensão $(25,8 \%)$, a PCR 
foi considerada um evento com ocorrência de 1 em cada 7292 sessões de diálise ${ }^{22}$.

\section{Alocação nos grupos}

Alocamos os participantes em 3 grupos com periodicidades de intervenção diferentes: grupo A (participantes não expostos à intervenção periódica); grupo B (intervenção periódica a cada 4 meses), grupo C (intervenção periódica a cada 2 meses).
Todos os participantes receberam uma intervenção inicial e outra no desfecho após 8 meses. Cada grupo de intervenção foi subdividido em 2 equipes com 4 membros cada uma, a formação de equipes possibilitou uma melhor divisão de tarefas dos mesmos durante a RCP simulada (Figura 1).

Fizemos a distribuição dos participantes em cada grupo de maneira aleatória, utilizando envelopes
Inclusão

Formação inicial, alocação, e simulação inicial

Simulação 2 meses

Simulação 4 meses

Simulação 6 meses

Simulação 8 meses

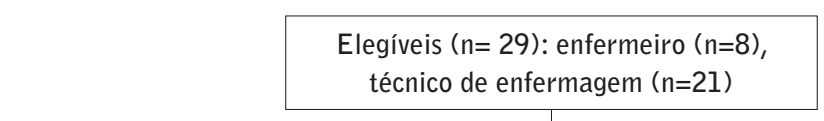

Excluídos $(n=5)$

- Não aceitou participar ( $*$ TE $n=2$ )

- Licença prolongada ( ${ }^{E} E N F n=1$ TE $n=1$ )

-Atuação exclusiva na gestão (ENF $n=1$

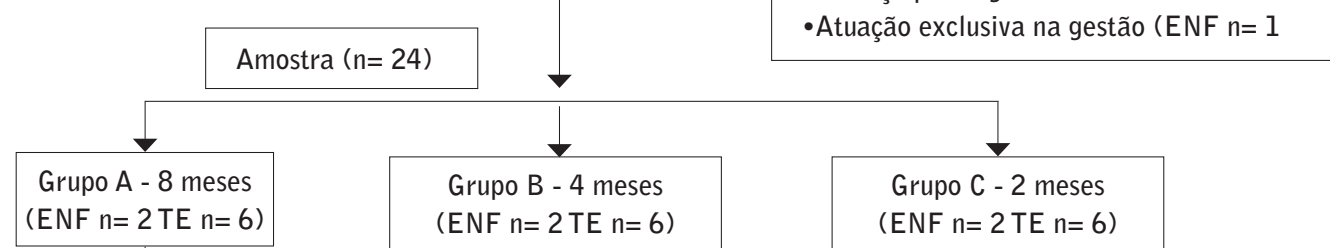

*Perda

(ENF $n=1$ TE $n=3$ )

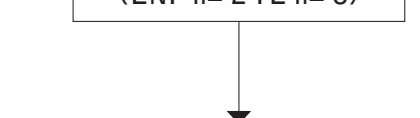

Simulação 2 (ENF $n=2$ TE $n=6$ )

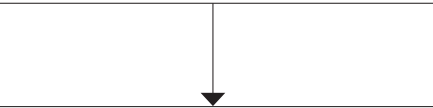

Simulação 4 (ENF $n=2$ TE $n=6$ )

Simulação 4 ( $E N F n=2 T E n=6$ )

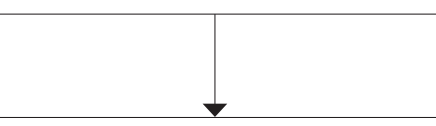

Simulação 6 (ENF $n=2$ TE $n=6$ )

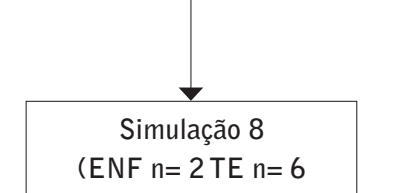

Avaliação final $(n=20)$

*TE - Técnico de enfermagem

*ENF - Enfermeiro

*Não realizaram a simulação inicial

Figura 1. Alocação dos participantes dentro dos grupos, e fluxograma de intervenções. 
opacos para cada periodicidade de treinamento e categoria profissional (enfermeiro ou técnico de enfermagem), e outro envelope para a escolha da equipe de atendimento. A decodificação dos envelopes foi feita por um indivíduo que não pertencia à equipe de pesquisa.

\section{Intervenção}

A formação inicial, foi realizada pelo Serviço de Educação Permanente do hospital por meio de um curso teórico-prático, e configurou-se em uma ação de capacitação interna que teve como objetivo desenvolver - conhecimento, e as habilidades necessárias para realizar a RCP. 0 curso foi ministrado por uma instrutora com certificação em Suporte Avançado de Vida em Cardiologia (SAVC), de um centro credenciado pela AHA no Brasil. 0 conteúdo programático contemplou as manobras de suporte básico de vida (SBV) e SAVC conforme protocolos da AHA/ERC, e pontos importantes do atendimento ao paciente em unidades de diálise de acordo com as recomendações publicadas pela $\mathrm{ERC}^{23}$.

Projetamos o cenário de simulação in situ, o qual está ilustrado na Figura 2, para durar 10 minutos com mais 10 minutos de discussão (debriefieng). Na sessão de HD simulada utilizamos equipamentos e materiais reais e um manequim de baixa fidelidade. As intervenções não foram filmadas. Os instrumentos utilizados para avaliar as competências foram desenvolvidos de acordo com as diretrizes da AHA e ERC, sem focar no ambiente de diálise, com abrangência nas competências em RCP

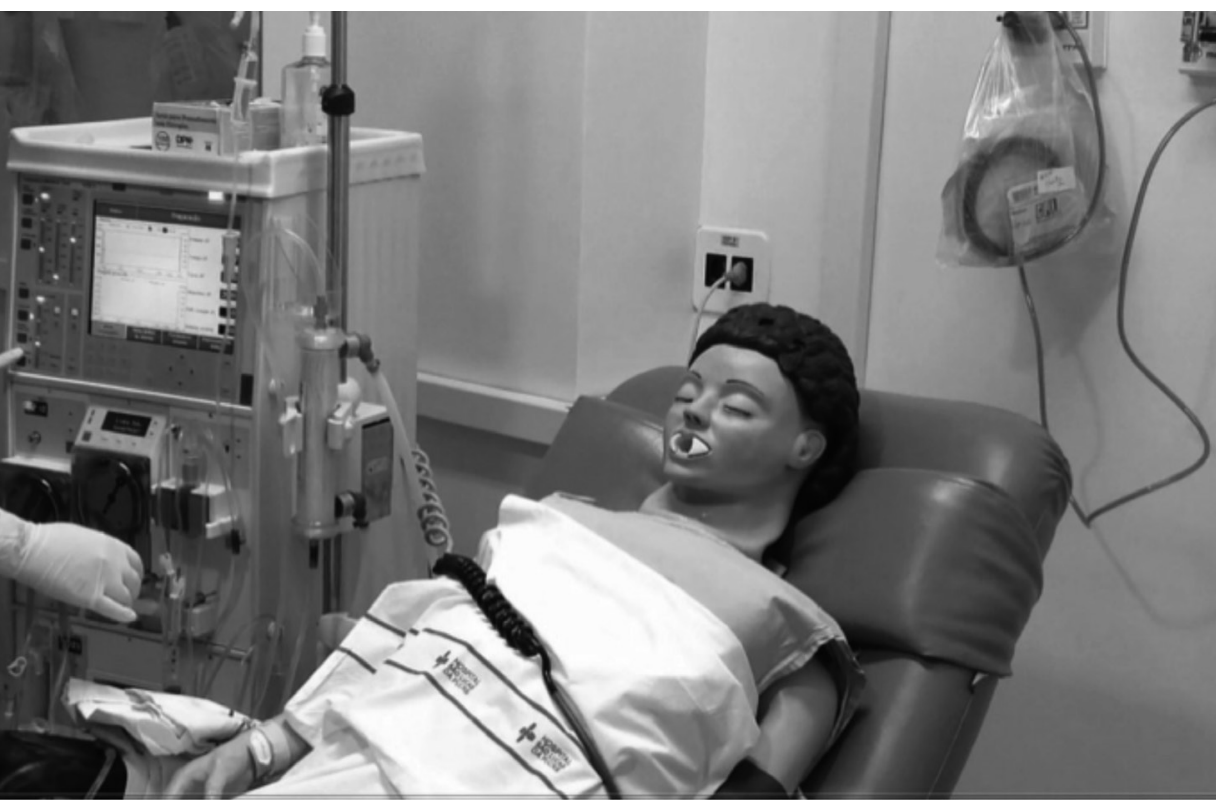

Figura 2. Cenário de simulação in situ na unidade de diálise. para todos os contextos assistenciais. Um questionário foi aplicado para analisar o perfil demográfico dos participantes.

Para a avaliação do conhecimento do participante elaboramos um teste de conhecimento por meio de pré e pós teste, baseado nos principais conhecimentos sobre RCP abordados na formação inicial. 0 teste estava composto por quatro questões de múltipla escolha, com sua sequência modificada no pós teste com o intuito de minimizar o efeito memória. Os objetivos instrucionais abordados foram: reconhecimento da PCR e primeiras ações; ênfase nas compressões torácicas; principais ritmos cardíacos e seus tratamentos; e terapia medicamentosa na PCR. Para verificar a presença de erros nas questões, aplicou-se o questionário para um total de 10 profissionais de enfermagem de outras áreas do hospital.

Avaliamos as habilidades com uma lista de verificação. 0 instrumento foi testado para verificar sua aplicabilidade e presença de erros em uma calibração do cenário de simulação com a presença dos autores e de observadores voluntários. Previamente esses observadores receberam uma formação referente ao instrumento a ser preenchido com o intuito de promover uma avaliação uniforme por parte deles. Em cada intervenção participaram 2 observadores que avaliaram os participantes na realização de cada habilidade conforme a posição assumida pelo mesmo durante 0 atendimento na simulação.

Os itens de checagem são descritos abaixo com seus respectivos critérios de aptidão:

- Constatação da PCR em, no máximo, 10 segundos: Verificação da responsividade do paciente, presença de movimento torácico e verificação de pulso carotídeo;

- Técnica da compressão torácica: Frequência das compressões torácicas de 30 compressões em, no mínimo, 15 segundos e, no máximo, 18 segundos; técnica da compressão torácica (posição das mãos, minimização de interrupções, revezamento dos profissionais); colocação de uma tábua para proporcionar uma superfície rígida antes do início das compressões.

- Técnica de ventilação com ressuscitador manual: Realizada com posicionamento da máscara facial com a mão em "C+E"; técnica de abertura das vias aéreas em todos os ciclos de ventilação; 
colocação de 02 no insuflador manual no início do atendimento; administração de 2 ventilações no intervalo das compressões durante 1 segundo cada ventilação;

- Monitorização e auxílio à desfibrilação: Conexão do paciente ao monitor desfibrilador no início do atendimento e a utilização adequada do equipamento quando necessário desfibrilar.

- Controle dos tempos e comunicação em circuito fechado: Controle do tempo de verificação do ritmo cardíaco a cada 2 min e se comunicou à equipe.

\section{Análise estatística}

Para a apresentação dos resultados utilizamos a estatística descritiva, compondo distribuições de frequência absoluta e relativa, médias, desvios-padrão e mediana. A medida de resultado das competências se deu por meio dos cálculos de acertos nas questões de conhecimento, antes e após a formação inicial e na simulação desfecho, e assertividade na realização das habilidades em cada simulação.

Determinamos a significância dos resultados entre os grupos utilizando testes não paramétricos na comparação das variáveis contínuas entre grupos, em função do reduzido tamanho de amostra e uma distribuição anormal. Utilizamos o teste de Kruskal Wallys - Post Hoc Dunn, e para as comparações intra grupo sobre as avaliações pré e pós intervenção, o teste de Wilcoxon. Ainda nas análises intra grupo, calculamos o tamanho do efeito das intervenções realizadas (formação inicial, e simulações), para comparação entre as diferenças de médias das avaliações de conhecimento pré e pós determinado a partir do f2 de Cohen.

0 nível de significância adotado em todas as análises foi de $5 \%$.

\section{Aspectos éticos}

A pesquisa foi aprovada pelo Comitê de Ética em Pesquisa da Universidade Federal de Ciências da Saúde de Porto Alegre, CAAE n ${ }^{\circ}$ 56516216.9.0000.5345, e da Pontifícia Universidade Católica do Rio Grande do Sul / PUCRS, CAAE n ${ }^{\circ}$ 56516216.9.3001.5336. 0 protocolo de pesquisa foi registrado no Sistema de Resultados do ClinicalTrials.gov (PRS) Protocolo NCT03626272. Nenhum conflito de interesse é declarado pelo (s) autor (es). Os participantes após receberem esclarecimento sobre o propósito da pesquisa e os aspectos éticos, assinaram um Termo de Consentimento Livre e Esclarecido.

\section{Resultados}

\section{Caraterização da amostra}

Relativamente à experiência profissional, a mediana em anos foi menor no grupo A 8,00 anos (mínimo de 3 e máximo de 25 anos), comparativamente ao grupo B 12,00 anos (mínimo de 9 e máximo de 29 anos) e C 12,50 anos (mínimo de 5 e máximo de 25 anos). Em relação à mediana em anos de atuação na unidade, observou-se uma maior atuação no grupo C 8,50 anos (máximo de 3 e máximo de 23 anos) em comparação aos grupos A 5,00 anos (mínimo de 3 e máximo de 16 anos) e B 6,60 anos (mínimo de 2 e máximo de 19 anos). Constatamos também que, dos 20 participantes que responderam ao questionário, 15 não haviam realizado curso de atendimento à $\mathrm{PCR}$ no último ano antes do estudo, contudo todos participaram do curso de formação oferecido no início da pesquisa. A Tabela 1 apresenta os resultados referentes ao perfil da amostra.

\section{Conhecimento sobre RCP}

$\mathrm{Na}$ item do conhecimento sobre a RCP verificamos que, após a formação inicial, quando comparados os resultados da análise dos testes de conhecimento (Tabela 2) entre os grupos, os mesmos apresentaram diferença estatisticamente significativa $(p=0,044)$. Esta significância estatística também foi detectada na análise dos resultados dentro do grupo $B(p=0,047)$.

Quando estimado o tamanho do efeito das intervenções, observamos que o efeito da formação inicial no grupo $B$, foi classificado como muito grande $(d=1,439$; IC95\%: 1,241 - 1,636), enquanto que, sobre os grupos A $(d=0,576$; IC $95 \%: 0,496-0,655)$ e $C(d=0,223$; IC95\%: 0,192-0,254), os tamanhos de efeito foram classificados como médio e pequeno, respectivamente. $\mathrm{Na}$ aplicação do teste na simulação de desfecho, as médias de todos os grupos elevaram-se em relação às médias obtidas após a formação inicial (Tabela 2).

\section{Habilidades para RCP}

$\mathrm{Na}$ demonstração de habilidades para RCP destacouse a pontuação observada em relação ao cumprimento de cada habilidade de forma correta, no contexto geral dos grupos. Constatamos resultados estatisticamente significativo nas médias de 2 habilidades: Na técnica da compressão torácica foi significativamente maior $(p=0,048)$ no grupo de periodicidade de 4 meses(grupo B) enquanto que a técnica da ventilação foi significativamente menor $(p=0,036)$ no grupo de periodicidade de 8 meses (grupo A). 0 tempo médio em que as compressões torácicas foram realizadas 
Tabela 1. Distribuição absoluta e relativa para o sexo, categoria profissional e curso RCP; e média, desvio padrão e mediana para a idade, experiência profissional e tempo de atuação na unidade, por grupos.

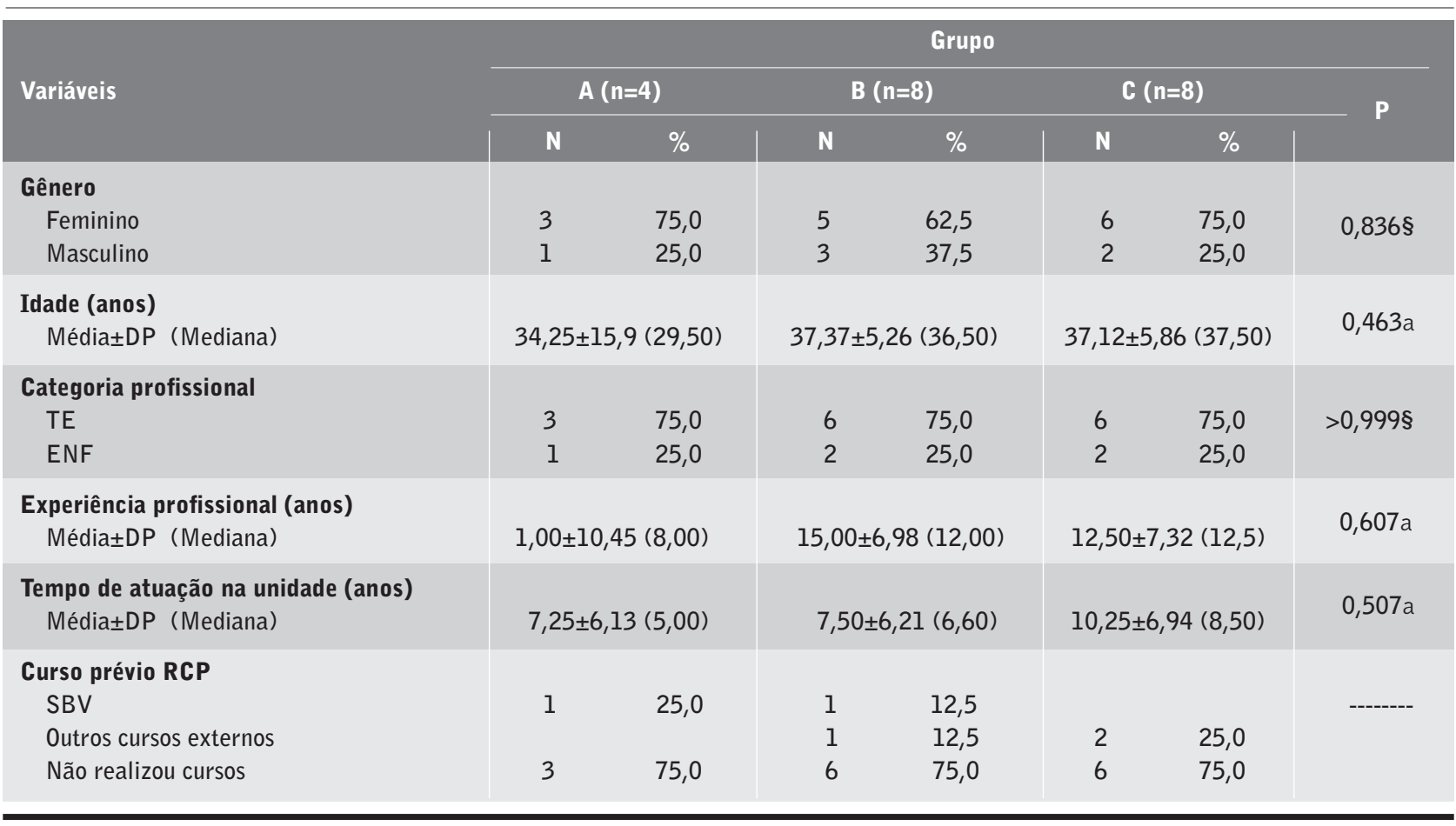

§: Teste Exato de Fisher (Simulação de Monte Carlo). ENF: enfermeiro.

a: Teste de kruskal Wallys.

SBV: Suporte Básico de Vida.

TE: técnico de enfermagem.

permaneceu dentro dos parâmetros preconizados pela AHA e ERC: de 15 a 18 segundos, com resultado discretamente inferior no grupo de periodicidade de 4 meses $(14,71 \pm 3,96)$ segundos, sem diferença estatística (Tabela 3).

\section{Discussão}

Observamos aumento das médias de acertos no pós teste de conhecimento, com significância estatística ( $p=0,044$, e $p=0,047$ ), no grupo de periodicidade de 4 meses. Este achado elucidou a necessidade dos participantes de atualização nas diretrizes em RCP, tendo em vista que a RCP de alta qualidade contribui para a diminuição da mortalidade e/ou sequelas para os pacientes, e deve ser desenvolvida por meio da educação profissional ${ }^{12}$. Fica clara a importância do planejamento e implementação periódica de um programa de educação permanente, nas unidades de diálise.

Pelos resultados do pós teste aplicado no desfecho da pesquisa, constatamos que o conhecimento construído na formação inicial foi sustentado por um período de 8 meses independente da periodicidade de simulação in situ. Em outros estudos também foi verificado que a simulação foi relevante para a manutenção do conhecimento quando comparada a nenhuma intervenção independente do intervalo em que foi realizada, do tipo de simulação (em centros de simulação, ou in situ), ou das tarefas realizadas no cenário ${ }^{24-26}$. Diferentes estudos apoiam o fato do conhecimento deteriorar-se menos que as habilidades ao longo do tempo ${ }^{19,27}$, identificamos nessa pesquisa que a oportunidade da prática, implícita à aprendizagem experiencial, permite que o profissional confronte, compare, amplie, revise e reflita sobre o conhecimento teórico, e com isso, contribui para a prevenção do declínio do mesmo por toda extensão longitudinal.

Observamos uma lacuna na literatura em relação a estudos com foco no intervalo de formação em RCP específicos para 0 ambiente de diálise. Todavia, a neonatologia desenvolveu estudos voltados para a comparação de habilidades em RCP em grupos expostos a diferentes intervalos de simulação in situ, os quais demonstraram melhoria na execução dessas habilidades, inclusive nos grupos expostos à menores intervalos, porém sem diferenças significativas nos resultados ${ }^{28,29}$. 
Tabela 2. Descrição das avaliações de conhecimento pré e pós formação teórica e na simulação de desfecho.

\begin{tabular}{|c|c|c|c|c|c|c|c|c|c|c|}
\hline \multirow{3}{*}{ Teste de conhecimento } & \multicolumn{9}{|c|}{ Grupo } & \multirow[b]{3}{*}{$\mathrm{p} \S$} \\
\hline & \multicolumn{3}{|c|}{$A(n=4)$} & \multicolumn{3}{|c|}{$B(n=8)$} & \multicolumn{3}{|c|}{$C(n=8)$} & \\
\hline & Média & $\begin{array}{l}\text { Desvio } \\
\text { padrão }\end{array}$ & Mediana & Média & $\begin{array}{l}\text { Desvio } \\
\text { padrão }\end{array}$ & Mediana & Média & $\begin{array}{l}\text { Desvio } \\
\text { padrão }\end{array}$ & Mediana & \\
\hline $\begin{array}{l}\text { FT } \\
\text { Pré } \\
\text { Pós }\end{array}$ & $\begin{array}{c}0,31 \\
0,50 b\end{array}$ & $\begin{array}{c}0,24 \\
0,25 \\
0.655\end{array}$ & $\begin{array}{l}0,38 \\
0,50\end{array}$ & $\begin{array}{c}0,41 \\
0,82 \mathrm{a}\end{array}$ & $\begin{array}{c}0,33 \\
0,24 \\
0.047\end{array}$ & $\begin{array}{l}0,38 \\
1,00\end{array}$ & $\begin{array}{c}0,29 \\
0,46 b\end{array}$ & $\begin{array}{l}0,27 \\
0,22 \\
0.131\end{array}$ & $\begin{array}{l}0,00 \\
0,50\end{array}$ & $\begin{array}{l}0,706 \\
0,044\end{array}$ \\
\hline d Cohen (IC95\%)¥ & \multicolumn{3}{|c|}{$0,576(0,496-0,655)$} & \multicolumn{3}{|c|}{$1,439(1,241-1,636)$} & \multicolumn{3}{|c|}{$0,233(0,192-0,254)$} & \\
\hline $\begin{array}{l}\text { SD } \\
\text { Pré } \\
\text { Pós }\end{array}$ & $\begin{array}{l}0,83 \\
0,83\end{array}$ & $\begin{array}{r}0,14 \\
0,29 \\
>0,999\end{array}$ & $\begin{array}{l}0,75 \\
1,00\end{array}$ & $\begin{array}{l}0,86 \\
0,79\end{array}$ & $\begin{array}{l}0,20 \\
0,27 \\
0,458\end{array}$ & $\begin{array}{l}1,00 \\
1,00\end{array}$ & $\begin{array}{l}0,63 \\
0,72\end{array}$ & $\begin{array}{l}0,27 \\
0,25 \\
0,083\end{array}$ & $\begin{array}{l}0,50 \\
0,63\end{array}$ & $\begin{array}{l}0,170 \\
0,753\end{array}$ \\
\hline d Cohen (IC95\%) $¥$ & \multicolumn{3}{|c|}{$0,047(0,40-0,053)$} & \multicolumn{3}{|c|}{$-0,298(-0,339--0,257)$} & \multicolumn{3}{|c|}{$0,346(0,298-0,393)$} & \\
\hline
\end{tabular}

FT: formação teórica.

SD: simulação desfecho.

$£:$ Teste de Wilcoxon.
$¥$ : Estimativa do tamanho do efeito d de Cohen (dados pareados).

§: Teste de KruskalWallys - Post Hoc- Dunn (onde médias seguidas de letras iguais na mesma linha indicam ausência de diferença estatisticamente significativa a $5 \%$, representadas pelas letras $a / b$ ).

d de Cohen: Medidas de tamanho de efeito pelo método "d de Cohen" complementada pelo Intervalo de Confiança $95 \%$.

Tabela 3. Caracterização das habilidades realizadas segundo o grupo.

\begin{tabular}{|c|c|c|c|c|}
\hline \multirow[b]{2}{*}{ Habilidade para RCP/estatística } & \multicolumn{4}{|c|}{ Grupos } \\
\hline & Grupo A $(n=4)$ & Grupo B $(n=8)$ & Grupo C ( $n=8)$ & $\mathrm{P} \S$ \\
\hline $\begin{array}{l}\text { Reconhecimento PCR } \\
\text { Média } \pm \text { DP (Mediana) }\end{array}$ & $0,75 \pm 0,35(0,75)$ & $0,83 \pm 0,47(1,00)$ & $0,60 \pm 0,22(0,50)$ & 0,687 \\
\hline $\begin{array}{l}\text { Colocação da tábua para CT } \\
\mathbf{n}^{0} \text { de intervenções (\%) } \\
\text { Intervenções realizadas } \\
\text { Corretamente }\end{array}$ & $\begin{array}{ll}2 & -- \\
1 & 50,0\end{array}$ & $\begin{array}{l}6 \\
4\end{array}$ & $\begin{array}{rr}10 & \cdots \\
7 & 70,0\end{array}$ & $-\cdots$ \\
\hline $\begin{array}{l}\text { Técnica da CT } \\
\text { Média } \pm D P \text { (Mediana)§ }\end{array}$ & $0,67 \pm 0,21(0,66)^{b}$ & $0,85 \pm 0,16(0,90)^{a}$ & $0,64 \pm 0,28(0,59)^{b}$ & 0,048 \\
\hline $\begin{array}{l}\text { Tempo de CT (seg) } \\
\text { Média } \pm \text { DP (Mediana) }\end{array}$ & $15,50 \pm 2,54(16,0)$ & $14,71 \pm 3,96(16,00)$ & $17,00 \pm 5,63(19,00)$ & 0,266 \\
\hline 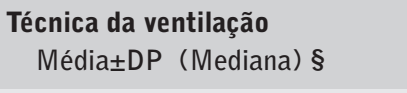 & $0,44 \pm 0,51(0,50)^{b}$ & $0,81 \pm 0,24(0,83)^{a}$ & $0,97 \pm 0,47(1,00)^{\mathrm{a}}$ & 0,036 \\
\hline $\begin{array}{l}\text { Monitorização - } \\
\mathbf{n}^{0} \text { de intervenções (\%) } \\
\text { Intervençoses realizadas } \\
\text { Corretamente }\end{array}$ & $\begin{array}{l}2 \\
0\end{array}$ & 50,0 & 80,0 & $-\cdots$ \\
\hline $\begin{array}{l}\text { Controle dos tempos } \\
\text { Média } \pm \text { DP (Mediana) }\end{array}$ & $0,75 \pm 0,35(0,75)$ & $0,75 \pm 0,42(0,80)$ & $0,33 \pm 0,41(0,45)$ & 0,256 \\
\hline $\begin{array}{l}\text { Desfibrilação } \\
\text { Média } \pm \text { DP (Mediana) }\end{array}$ & $1,00 \pm 0,00(1,00)$ & $0,83 \pm 0,41(0,85)$ & $0,93 \pm 0,15(0,87)$ & $>0,999$ \\
\hline
\end{tabular}

CT: compressão torácica.

§: Teste de KruskalWallys - Post Hoc- Dunn (onde médias seguidas de letras iguais na mesma linha indicam ausência de diferença estatisticamente significativa a 5\%, representadas pelas letras $\mathrm{a} / \mathrm{b}$ ). 
No entanto, no nosso estudo constatamos resultados estatisticamente significantes $(p=0,048)$ na prática de uma habilidade essencial para o sucesso da reanimação, como a técnica da compressão torácica no grupo que praticou a simulação de 4/4 meses.

Entendemos as diferenças entre neonatos e adultos em HD. Porém nestes dois contextos, existem particularidades que são importantes e que os tornam diferentes de outros grupos de pacientes, exigindo assim conhecimentos específicos para atuação dos profissionais. Nesse caso, o foco da presente investigação está no estudo da exposição dos enfermeiros e técnicos de enfermagem a diferentes intervalos de tempo face ao desempenho de habilidades durante a RCP em HD, e nos ambientes, tanto do de hemodiálise como de neonatologia, conforme foi relatado nos estudos 29,30 , a frequência de episódios de PCR é baixa, mas necessita de uma alta acuidade nas manobras de ressuscitação perante uma situação clínica que pode ser inesperada e de alto estresse.

Encontramos resultados significativos somente quando comparada a intervenção utilizando a simulação in situ com a ausência dela ${ }^{29}$ ou com formações tradicionais sem a oportunidade da prática por meio da simulação ${ }^{31}$. Esses resultados confirmam a importância da prática para a construção da aprendizagem. Nesse estudo também foi demonstrado que não é só a ausência de prática que pode influenciar na deterioração das habilidades, mas também a prática não periódica. Em nossa pesquisa verificamos uma perda significativa da habilidade de ventilação no grupo que não praticou de forma periódica a RCP, grupo $A_{,}(p=0,036)$.

Consideramos que, dentro da vertente da aprendizagem experiencial existem os princípios da continuidade, onde cada experiência incorpora ou modifica a qualidade de algo, promovendo a educação com crescimento; e da interação, o que justifica a aprendizagem no contexto (pessoas, coisas, ambiente) ${ }^{32}$. Nesse caminho, justifica-se a necessidade da prática para que ocorra a reflexão na ação. Outro ponto importante é que, a semelhança entre a formação e o ambiente de trabalho, tem papel importante no desenvolvimento de habilidades ${ }^{20}, \operatorname{logo}$, a simulação in situ pode contribuir também com a consolidação do aprendizado destas.

Observamos que a simulação in situ promoveu a construção do conhecimento e das habilidades se praticada a cada 4 meses como demonstrado nesse estudo $(p=0,048)$. Este fato provavelmente ocorreu pela oportunidade de os participantes contextualizarem a teoria ofertada no curso inicial, com a prática das habilidades no contexto de trabalho de forma reflexiva. Esse modelo de formação educacional demonstra estar em consonância com a recomendação da AHA e ERC, de oferecer formações mais frequentes e de baixa dose, ou seja, de curta duração, e prática continuada ${ }^{33,34}$.

0 nosso estudo apresenta limitações uma vez que os resultados são representativos de uma pequena amostra de um único hospital, porquanto, não podem ser validados externamente com precisão. Ainda, os instrumentos não foram validados com padrões necessários para obtenção de predição ou inferência. Outra limitação refere-se à exploração das variáveis em uma categoria profissional (enfermagem) classificada em nível técnico e superior, (possuem formação, funções e responsabilidades diferentes). Uma abordagem multiprofissional também se faz necessária devido ao caráter interpessoal da $R C P$, e a possibilidade de enriquecimento do estudo. Sugerimos que em estudos posteriores, seja incluidos outros profissionais, nomeadamente, médicos devido à responsabilidade específica que os mesmos possuem durante 0 atendimento.

Por meio da presente pesquisa analisamos uma estratégia de formação permanente de profissionais que é eficiente em termos de tempo, recursos e contribuição com a construção do aprendizado. Não existindo diferenças significativas em relação a amostra, sugere-se a possibilidade de ser generalizada a outras equipes de enfermagem semelhantes, principalmente nas áreas em que o evento da PCR não é frequente, mas pode ocorrer pela complexidade do paciente. Através da interpretação dos resultados sugerimos que a simulação in situ aplicada em intervalos a cada 4 meses, demonstrou ser uma metodologia eficaz que enunciou um progresso em duas direções. Por um lado, em relação às pontuações dos testes iniciais de conhecimento e por outro lado a consolidação de competências (conhecimento e habilidade) em RCP no contexto da HD. Contudo, serão necessários mais estudos sobre os desafios e particularidades que o pessoal das unidades de diálise enfrentam no atendimento à uma PCR para nortear o desenvolvimento de intervenções que possam aprimorar a RCP nesse ambiente.

Recibido: 29-01-20

Revisado: 27-04-20

Modificado: 23-05-20

Aceptado: 04-08-20 


\section{Bibliografía}

1. Passman R. Prevention of sudden cardiac death in dialysis patients: drugs, defibrillators or what else? Blood Purif. 2013;35:49-54.

2. Hersog CA, Mangrum M, Passman R. Sudden cardiac death and dialysis patients. Semin Dial 2008; 21(4):300-7.

3. Karnik JA, Young BS, Lew NL, Herget M, Dubinsky C, Lazarus JM et al. Cardiac arrest and sudden death in dialysis units. Kidney Int. 2001;60:350-7.

4. Vázquez E, Sánchez-Perales C, García-García F, García-Cortés MJ, Torres J, Borrego F et al. Sudden death in incident dialysis patients. Am J Nephrol. 2014:39:331-6.

5. Wang AY-M, Lam CW-K, Chan IH-S, Wang M, Lui S-F, Sanderson JE. Sudden cardiac death in end-stage renal disease patients a 5 -year prospective analysis. Hypertension 2010; 56:210-6.

6. Genovesi S, Boriani G, Covic A, Vernooij RWM, Combe C, Burlacu A et al. Sudden cardiac death in dialysis patients: different causes and management strategies. Nephrol Dial Transplant. 2019 Sep 20:gfz182. [En prensa]

7. Davis TR, Young BA, Eisenberg MS, Rea TD, Copass MK, Cobb LA. Outcome of cardiac arrests attended by emergency medical services staff at community outpatient dialysis centers. Kidney Int. 2008;73:933-9.

8. Hersog CA. Cardiac arrest in dialysis patients: approaches to alter an abysmal outcome. Kidney Int. 2003;63(Suppl 84):S197-200.

9. Wong SPY, Kreuter W, Curtis JR, Hall YN, O'Hare A.M. Trends in In-Hospital Cardiopulmonary Resuscitation. JAMA Intern Med. 2015;175(6): 1028-35.

10. Pun $P H$, Dupre ME, Starks MA, Tyson C, Vellano $K$, Svetkey LP et al. Outcomes for hemodialysis patients given cardiopulmonary resuscitation for cardiac arrest at outpatient dialysis clinics. J Am Soc Nephrol. 2019 Março; 30(3):461-70.
11. National Kidney Foundation: Diretrizes de Prática Clínica da Iniciativa de Qualidade de Resultados de Doenças Renais (KDOQI) para doenças cardiovasculares em pacientes em diálise: Diretriz 8 Desfibrilação externa. [Internet] 2005 [Consultado 25 abr 2020]. Disponível em: http://kidneyfoundation. cachefly.net/professionals/KD0QI/guidelines_cvd/ index.htm.

12. American Heart Association. Destaques da American Heart Association 2015: Atualização da Diretrizes de RCP e ACE. [Internet] 2015 [Consultado 12 set 2019] [aprox. 36 p.]. Disponível em:https://eccguidelines.heart.org/wp-content/ uploads/2015/10/2015-AHA-Guidelines-Highlights-Portuguese.pdf.

13. Borges BLC, Machado AAV. Problematizando a assistência de enfermagem durante ressucitação cardiopulmonar em unidade de HD: desafio para o enfermeiro educador. Interbio. 2007;1(2):38-43.

14. Martins JCA, Mazzo A, Mendes IAC, Rodrigues MA. A simulação no ensino de enfermagem. Coimbra: Unidade de Investigação em Ciências da Saúde: Enfermagem. [Internet] 2014 [Consultado 9 out 2019] [aprox. 310 p.]. Disponível em: https:// web.esenfc.pt/v02/pa/conteudos/downloadArtigo. php?id_ficheiro $=730$.

15. Rosen MA, Hunt EA, Pronovost PJ, Federowicz MA, Weaver SJ. In Situ Simulation in Continuing Education for the Health Care Professions: A Systematic Review. J Contin Educ Health Prof. 2012; 32(4):243-54.

16. Kalaniti K. In situ simulation: let's work, practice and learn together. Acta Paediatr. 2014;103(12): 1219-20.

17. Mondrup F, Brabrand M, Folkestad L, Oxlund J, Wiborg KR, Sand NP, Knudsen T. In-hospital resuscitation evaluated by in situ simulation: a prospective simulation study. Scand J Trauma Resusc Emerg Med. 2011 0ct 6;19:55.

18. Van Schaik SM, Plant J, Diane $S$, Tsang L, $0^{\prime}$ SuIlivan P. Interprofessional Team Training in Pediatric Resuscitation: A Low-Cost, In Situ Simulation Program That Enhances Self-Efficacy Among Participants. Clin Pediatr (Phila) 2011;50(9):80715. 
19. Yang CW, Yen ZS, McGowan JE, Chen HC, Chiang WC, Mancini ME et al. A systematic review of retention of adult advanced life support knowledge and skills in healthcare providers. Resuscitation 2012;.83(9):1055-60.

20. Conway JM. Factors that influence skill decay and retention: A quantitative review and analysis. Hum Perform. 1998;11(1):29-55.

21. Thomé FS, Sesso RC, Lopes AA, Lugon JR, Martins CT. Inquérito brasileiro de diálise crônica 2017. Braz. J. Nephrol. 2019;41(2):208-14.

22. Meira FS, Figueiredo $A E$, Zemiarcki J, Pacheco J, Poli de Figueiredo CE, d'Avila DO . Two Variable Sodium Profiles and Adverse Effects During Hemodialysis: A Randomized Crossover Study. Ther Apher Dial 2010;.14(3):328-33.

23. Truhlár`A, Deakin $C D$, Soar J, Khalifa GEA, Alfonzo A, Bierens JJLM. European Resuscitation Council guidelines for resuscitation 2015 section 4. Cardiac arrest in special circumstances. Resuscitation 2015; 95:148-201.

24. Mundell WC, Kennedy CC, Szostek JH, Cook DA. Simulation technology for resuscitation training: $A$ systematic review and meta-analysis. Resuscitation 2013;84(9):1174-83.

25. Bingham AL, Sen S, Finn LA, Cawley MJ. Retention of advanced cardiac life support knowledge and skills following high-fidelity mannequin simulation training. Am J Pharm Educ. 2015;.79(1):12.

26. Tawalbeh LI, Tubaishat A. Effect of Simulation on Knowledge of Advanced Cardiac Life Support, Knowledge Retention, and Confidence of Nursing Students in Jordan. J Nurs Educ. 2014; 53(1):38-44.

27. Smith KK, Gilcreast D, Pierce K. Evaluation of staff's retention of ACLS and BLS skills. Resuscitation 2008;.78(1):59-65.
28. Cepeda Brito JR, Hughes PG, Firestone KS, Ortiz Figueroa $F$, Johnson $K$, Ruthenburg $T$ et al. Neonatal Resuscitation Program Rolling Refresher: Maintaining Chest Compression Proficiency Through the Use of Simulation-Based Education. Adv Neonatal Care. 2017;17(5):354-61.

29. Rubio-Gurung $S$, Putet G, Touzet $S$, Gauthier-Moulinier $\mathrm{H}$, Jordan I, Beissel $\mathrm{A}$ et al. In situ simulation training for neonatal resuscitation: an RCT. Pediatrics 2014;134(3):790-7.

30. Carolan-Olah M , Kruger G, Brown V , Lawton F, Mazzarino M . Development and evaluation of a simulation exercise to prepare midwifery students for neonatal resuscitation. Nurse Educ Today 2016;36: 375-80.

31. Sullivan NJ, Duval-Arnould J, Twilley M, Smith $S P$, Aksamit D, Boone-Guercio $P$ et al. Simulation exercise to improve retention of cardiopulmonary resuscitation priorities for in-hospital cardiac arrests: A randomized controlled trial. Resuscitation 2015;86:6-13.

32. Dewey J. Experiência e Educação. São Paulo: Companhia Editora Nacional; 1971.

33. Bhanji F, Finn JC, Lockey A, Monsieurs K, Frengley $\mathrm{R}$, Iwami $\mathrm{T}$ et al. Part 8: Education, implementation, and teams: 2015 international consensus on cardiopulmonary resuscitation and emergency cardiovascular care science with treatment recommendations. Circulation 2015; 132(Suppl 2):42-68.

34. Greif R, Lockey AS, Conaghan P, Lippert A, De Vries W, Monsieurs KG et al. European Resuscitation Council Guidelines for Resuscitation 2015. Section 10. Education and implementation of resuscitation. Resuscitation 2015;95:288-301.

Este artículo se distribuye bajo una Licencia Creative Commons Atribución-NoComercial 4.0 Internacional. https://creativecommons.org/licenses/by-nc/4.0/ 